
e.mail: h.stratton@griffith.edu.au mCCDA agar

Tel: $(+61) 737355503$

\section{stabilisation pond}

Maxim Sheludchenko², Anna Padovan ${ }^{3}$, Mohammad Katouli ${ }^{2}$, Anne Roiko $^{4}$ and Helen Stratton $^{1}$

${ }^{1}$ School of Environment and Science, Griffith University, Nathan, Queensland

${ }^{2}$ Genecology Research Centre, University of the Sunshine Coast, Sippy Downs, Queensland, ${ }^{3}$ Research Institute for the Environment and Livelihoods, Charles Darwin University, Darwin, Northern Territory, Australia

${ }^{4}$ School of Medicine \& Menzies Health Institute, Griffith University Gold Coast, Queensland

Keywords: Waste Stabilization Pond (WSP), Acinetobacter baumanii, bacterial survival,

Corresponding author: Associate Professor Helen Stratton, School of Environment and Science, Building N34, Griffith University, Nathan, Queensland 4111

21 


\section{Abstract}

Acinetobacter baumannii survives for prolonged periods under a wide range of environmental conditions. In a larger study investigating the efficacy of pathogen removal in a waste stabilization ponds (WSP), we cultivated microbes from wastewater samples on mCCDA agar containing selective and recommended supplements for the growth of Campylobacter. This bacterium is a recommended reference pathogen for the verification and validation of water recycling schemes in Australia and other parts of the world. A high number of colonies characteristic of Campylobacter grew on the selective media but this did not correlate with qPCR data. Using primers targeting the16S rRNA gene, and additional confirmatory tests such as detection of VS1, ompA, bla OXA-51-like, bla OXA-23-like genes, we tested eight random colonies from eight samples (64 colonies in total) and identified them as A. baumannii. Wastewater grab samples taken three times over 6 months throughout the WSP system showed removal of $A$. baumannii in the WSP atrates similar to E. coli. In contrast, further intensive sampling from the inlet and the outlet of the WSP using a refrigerated auto-sampler showed that the number of $A$. baumannii in most sampling rounds did not differ significantly between the inlet and outlet of the WSP and that there was high variation between replicates at the outlet only. Resistance genes were detected in most $A$. baumannii isolated from the waste stabilisation pond and may potentially be a source of antibiotic resistance for environmental strains. 
Waste stabilization pond (WSP) systems are used widely for the treatment of domestic wastewater in developing countries due to low cost and easy maintenance ${ }^{1}$. A typical WSP system consists of two lagoon types: facultative and maturation pond(s). Often, raw sewage goes directly into a 1.5-2 $\mathrm{m}$ deep facultative pond with a retention time of about 7-10 days, after which the wastewater flows into a baffled or non-baffled maturation pond with a longer retention time. As reported earlier, pathogenic strains such as Salmonella enterica and Campylobacter jejuni could be removed in a facultative pond and may not be present any longer in the maturation pond effluent ${ }^{2}$. Nevertheless, it remains interesting how pathogenic Campylobacter spp. survive in the environment, as the bacterium is a foodborne pathogen and is also a major cause of water-borne diarrhoeal outbreaks ${ }^{3}$. The Australian water recycling guidelines (AWRG) recommend monitoring Campylobacter as a reference bacterial pathogen together with faecal indicators and other reference pathogens such as adenovirus and oocysts of Cryptosporidium ${ }^{4}$. However, routine testing for Campylobacter spp. in wastewaters using culture-based methods often yields biased results due to the growth of other species (Judy Blackbearrd, Melbourne Water, Australia; personal communication).

Selective media such as Bolton, Preston and mCCDA agars for the detection of Campylobacter spp. have been used in many studies involving food-borne diarrheal outbreaks ${ }^{5-7}$. However, the use of these media and their specificity for detection of $C$. jejuni in environmental samples has been questioned ${ }^{8-10}$. It is known that other bacterial species such as E. coli, Proteus spp., Acinetobacter spp. ${ }^{11}$ as well as Helicobacter spp., Arcobacter spp., Sutterella wadswortheness and Bordetella pertussis ${ }^{12}$ produce characteristic grey colonies of Campylobacter on these selective media and can be counted as false positives. 
detect the presence of Campylobacter spp. in a WSP, we observed a high number of colonies with characteristics of Campylobacter spp. on mCCDA agar plates that did not corresponded with the results of qPCR on the same samples. We employed 16S rRNA sequencing together with species-specific primers to characterise a high number of these colonies. The results confirmed that these colonies were mainly Acinetobacter baumannii. We then performed an intensive sampling from the inlet and the outlet of this WSP using both grab sampling and auto-samplers and tested for the presence of $A$. baumannii using the above methods. The implications of collecting samples using auto-samplers and utilising the mCCDA medium for the identification of $C$. jejuni for the enumeration of pathogenic bacteria in the effluent of waste stabilization ponds is discussed, particularly in light of long term monitoring of $A$.

\section{baumannii.}

\section{Results and Discussion}

During a study investigating pathogen removal in waste stabilisation ponds, we noticed a lack of correlation between the number of presumed Campylobacter spp. based on mCCDA agar (supplemented with polymyxin B to reduce growth of Gram-negative bacteria) and qPCR data of the same samples. We suspected that the mCCDA agar plates were supporting the growth of non-campylobacter species and sequencing of the 16s rRNA gene of colonies isolated from the mCDDA plates showed that they were in fact A. baumannii.

Monthly replicate grab samples were collected from the inlet and six sites throughout the baffled WSP pond, as well as from constructed wetlands $(\mathrm{CW})$ and reed beds $(\mathrm{RB})$ that were a part of the treatment chain following the WSP. Analysis of these samples demonstrated a reduction in the number of $A$. baumannii as determined by membrane filtration on mCCDA agar and was strongly correlated with the faecal indicator, E. coli during all observations (Figure 1). To monitor pond performance, we also counted the number of E. coli, a 
conventional faecal indicator bacterium, in all samples. The major reduction of $A$. baumannii occurred at the beginning of the WSP system i.e. at sites $\mathrm{H} 1$ to $\mathrm{H} 3$ and where the effluent entered the RB after passing through $\mathrm{CW}$, as described in the methods. The initial numbers of A. baumannii in influent samples were $2 \operatorname{logs}$ lower than $E$. coli, though the removal rates remained the same, suggesting that $E$. coli can be used as an acceptable indicator for monitoring changes of Acinetobacter in such maturation ponds.

Using the auto-sampler, we sampled wastewater intensively from the inlet and outlet of the WSP throughout February and March 2015 to monitor faecal indicators and pathogens over a long-time period. Most pond monitoring is done monthly but we wanted to determine whether bacterial concentrations and their removal rates changed over time. The number of E. coli in almost all samples collected from the inlet were between 1-2 logs higher than $A$. baumannii (Figure 2A) as was observed during grab sampling in 2014. E. coli numbers varied from 3.45 to $6.31 \log$ in the inlet and from 1.15 to $3.92 \log$ at the outlet with a consistent 2-3 log reduction in E. coli numbers observed throughout the sampling (Figure 2B). In contrast to the observations made in 2014 using grab samples, the reduction of $A$. baumannii varied in the effluent samples and the concentration of $A$. baumannii was mostly lower than that of E. coli (Figure 2B). During the first 48 hrs sampling in February (3 samples per day) we observed a 1-2 log reduction in the number of $A$. baumannii. However, from 10 February 2015 (the third round of sampling) onwards, the number of $A$. baumannii were higher (1-2 log) than E. coli despite their lower initial numbers at the inlet. In addition, a large variation in the numbers of $A$. baumannii was observed between duplicate samples from the effluent, with higher concentrations observed in the first duplicate and lower concentrations in the second duplicate. This was not observed for E. coli. One possible explanation for this higher variation between duplicate samples is that pond water at the outlet site had to pass through 7 meters of tubing before it reached the auto-sampler and this 
may have contributed to bacterial growth inside the tubing. The auto-sampler has a backwashing function to avoid collecting remnant water, however, it may not have worked sufficiently to eliminate these bacteria inside the tubing, causing higher numbers in the first sample. We postulate that the higher numbers of $A$. baumannii in outlet samples compared to the inlet could also be due to the biofilm formed by these bacteria inside the tubing. Acinetobacter spp. can form biofilms in different environments ${ }^{19-21}$. Thus, the use of autosamplers with long tubing may not be suitable for continuous monitoring of bacterial pathogens which can form biofilms.

To rule out the possibility that some of the isolates on the mCCDA plates could have been $C$. jejuni or other species such as C. ureolyticus, the second most common species of Campylobacter after C. jejuni in faecal specimens of patients ${ }^{22}$ and some animals ${ }^{23}$, we tested 539 isolates from mCCDA plates over four sampling events. The results showed that none of the colonies tested were positive for the $C$. jejuni VS1 specific marker or any of the other 14 molecular markers specific for other species of Campylobacter (see Supplementary Materials, Table S1).

Acinetobacter spp. and in particular A. baumanii have been reported in wastewater effluent ${ }^{24,}$ ${ }^{25}$ with antibiotic resistance shown to increase in these bacteria due to the selective pressure of the environment ${ }^{26}$. In the WSP studied here, we also identified a range of pharmaceuticals including antibiotics (see Supplemental Material Table S2). Therefore, we investigated antibiotic resistance of $A$. baumannii isolates from mCCDA plates by PCR, which was also another confirmation step for the identification of $A$. baumanii. Between $7^{\text {th }}$ of February and $10^{\text {th }}$ of March of 2015, an additional five rounds of grab sampling were performed at the inlet and outlet of the WSP. In all, 270 isolates from the inlet and 216 isolates from the outlet were tested for the presence of the A. baumannii specific antibiotic resistance markers ompA and two beta-lactamase genes i.e. oxa-51 and oxa-23. The results showed that $96 \%$ of the isolates 
were positive for the ompA marker (Figure 3). Shotgun metagenomics analysis also confirmed the presence of antibiotic resistant sequences of $A$. baumanii in DNA extracts from the same water samples.

A specific characteristic of $A$. baumanii strains is their susceptibility to carbapenemase antibiotics ${ }^{17}$. In our study, two of seven colonies taken from the same plate were positive for $b_{l a} A_{\text {oxa-51 }}$ and negative for bla $\mathrm{A}_{\text {oxa-23 }}$. Thus, we also confirmed the presence of $A$. baumanii in effluent wastewater with carbapenemase resistance. Recently, the World Health Organization (WHO) raised concerns about the presence of antibiotics in wastewater and the consequences of transfer of antibiotic resistance genes to environmental bacteria upon their exposure ${ }^{27}$. For this reason, A. baumanii maybe an important candidate for monitoring bacterial pathogens in WSPs.

To the best of our knowledge, this is the first report on the presence of antibiotic resistant strains of $A$. baumanii in a WSP system. The presence of a range of pharmaceuticals in the wastewater effluent from the studied maturation pond (see Supplemental Material Table S2) may contribute to the presence of antibiotic resistant strains of Acinetobacter. A. baumannii, despite being a weak pathogen compared to Pseudomonas aeruginosa, may play a significant role in spreading broad-spectrum resistance genes to other Gram-negative organisms ${ }^{28}$, especially under environmental conditions of waste stabilization ponds. In Australia's northern tropics, these bacteria are responsible for major cases of community-acquired pneumonia during the wet season ${ }^{29}$. The presence of clinically important strains of Acinetobacter in the environment is not known but few authors have reported antibiotic resistant bla OXA-23 A. baumannii in hospital wastewaters ${ }^{30}$, in filaments of active sludge of wastewaters ${ }^{31}$ and in paleosol contaminated with waste leakage ${ }^{32}$. A. baumanii can also be very persistent in the environment, requiring special treatment for inactivation ${ }^{33}$. 
In conclusion, we found that $A$. baumanii could grow on selective mCCDA plates supplemented with polymyxin B forming colonies characteristic of Campylobacter.

Therefore, the use of this medium for the detection and enumeration of Campylobacter spp.in wastewater or recycled water should be always accompanied by additional confirmatory tests.

We also found that $A$. baumanii is highly abundant in the studied maturation pond in subtropical Australia and some of these strains might carry antibiotic resistance genes. Finally, the use of auto-samplers may not be suitable for continuous monitoring of $A$. baumanii in wastewater systems due to their ability to form biofilms.

\section{Material and Methods}

\subsection{Site description and sample collection}

The WSP is located in subtropical South-East Queensland within a sub-urban community of 1500 inhabitants. Raw sewage with brief mechanical treatment is piped into a primary $65 \times$ $65 \times 1.5 \mathrm{~m}$ facultative pond and subsequently piped to a $30 \times 60 \times 1.2 \mathrm{~m}$ baffled maturation pond with 12-20 days of retention time for this pond. Two $30 \times 60 \mathrm{~m}$ constructed wetlands $(\mathrm{CW})$ and three $15 \times 20 \mathrm{~m}$ reed beds $(\mathrm{RB})$ aid to polish (further treat) the effluent of maturation pond.

Grab sampling was initially carried out on May, July and September 2014. Samples were collected in $500 \mathrm{~mL}$ bottles directly from the inlet pipe of the influent (i.e. Inlet), at $30 \mathrm{~cm}$ depth of the effluent pond at two and a half meters from the inlet site (H1), the edge of five baffles (H2 to $\mathrm{H} 6)$ as well as within $2 \mathrm{~m}$ of the outlet pipe (i.e. outlet). The second round of sampling was done in 2015 where two portable Avalanche refrigerated auto-samplers (Teledyne ISCO, US) were used to collect duplicate samples of pond water (900 $\mathrm{mL}$ each) at the inlet and outlet of the pond. Samples were collected by the auto-sampler every 8 hours during February-March 2015: 6:00 am, 2:00 pm and 10:00 pm, over 30 calendar days. All samples were sent to the laboratory on ice every second day to ensure analyses were carried 
out within 24-48 hours. At each sampling event, the averaged values of duplicate bacterial concentrations were used for data analysis, with missing values disregarded. Overall, there were 73 inlet data points and 71 outlet data points for enumeration of $E$. coli (colonies on mTEC agar) and $A$. baumannii (colonies on mCCDA plates).

\section{Culture-dependent enumeration by direct plating}

Individual wastewater samples were mixed thoroughly, serially diluted in sterile distilled water and filtered through $0.45 \mu \mathrm{m}$ sterile mixed cellulose ester membrane filters (Advantec, Tokyo, Japan) using a CombiSart ${ }^{\circledR}$ manifold filtration unit (Sartorius, Gottingen, Germany). For enumeration of E. coli, as an indicator bacterium, filters were placed on modified mTEC agar (BD, Sparks, AR, USA) and incubated at $35^{\circ} \mathrm{C}$ for 2 hours followed by incubation at $44.5^{\circ} \mathrm{C}$ for 24 hours. Magenta colonies were counted as E. coli.

For enumeration of Campylobacter spp. and Acinetobacter spp., filters were placed on bloodfree modified charcoal cefoperazone dexycholate agar (mCCDA, PO5091A, Oxoid, Basingstoke, UK) with antibiotic supplement (SR0155, Oxoid) as specified by the manufacturer. The antibiotic polymyxin B (SR0099, Oxoid) was also added to improve the manufacturer's protocol as recommended by Chon et al. ${ }^{11}$. Selective chromogenic-like Brilliant CampyCount agar (PO1185, Oxoid) plates were obtained for a trial with wastewaters samples. The selective mCCDA plates were combined with an enrichment step using Preston broth (Nutrient broth $\mathrm{N}^{\circ} 2$, CM0067, Oxoid) which was supplemented with 5\% lysed horse blood (SR0048, Oxoid) and antibiotic (SR0204 and SR0232E, Oxoid). Ten to fifty $\mathrm{mL}$ of influent and effluent were filtered through $0.45 \mu \mathrm{m}$ sterile mixed cellulose ester membrane filters (Advantec) using a CombiSart ${ }^{\circledR}$ manifold filtration unit (Sartorius). The membrane was either directly placed onto selective plates or aseptically folded into $45 \mathrm{~mL}$ enrichment broth in $50 \mathrm{~mL}$ sterile plastic tubes. The tubes were tightly closed and left for 48 
hours at $42^{\circ} \mathrm{C}$. After this incubation step, $200 \mu \mathrm{L}$ of the content was streaked onto mCCDA

218 plates. Plates were incubated at $43^{\circ} \mathrm{C}$ for 48 hours under microaerofilic conditions using

219 Campygen system (CN0025, Oxoid). All grey colonies were counted and eight of them were 220 selected for further analyses.

Identification of isolates by $16 \mathrm{~S}$ rDNA amplification

223 Universal primers $27 \mathrm{~F}$ and $\mathrm{U} 1492 \mathrm{R}^{13}$ were used to produce $16 \mathrm{SrDNA}$ amplicons in a PCR assay containing $1 \times$ DreamTaq $^{\mathrm{TM}}$ Master Mix (ThermoFisher Scientific, Sydney, Australia), $500 \mathrm{nM}$ forward and reverse primer, $5 \mu \mathrm{L}$ of DNA template in a total volume of $50 \mu \mathrm{L}$. Amplification reaction was performed in a C1000 thermal cycler (BioRad, Hercules, USA) with the following conditions: $95^{\circ} \mathrm{C}$ for $10 \mathrm{~min}$, followed by 25 cycles of $95^{\circ} \mathrm{C}$ for $10 \mathrm{~s}, 50^{\circ} \mathrm{C}$ for $5 \mathrm{~s}$ and $72^{\circ} \mathrm{C}$ for $1 \mathrm{~min}$ with a final elongation step at $72^{\circ} \mathrm{C}$ for $10 \mathrm{~min}$. PCR products were visualized on a $1 \%$ agarose gel stained with ethidium bromide and tubes containing PCR products of the correct size were purified using the QIAquick PCR Purification kit (Qiagen, Dusseldorf, Germany). Purified amplicons were directly sequenced (AGRF, Brisbane, Australia). The resulting 16SrDNA sequences were queried using the BlastN algorithm in GenBank for strain identification. Sequences were deposited in GenBank with accession numbers KU16092 and KU161093.

Gene specific real-time PCR screening

237 Sixty four randomly selected colonies were re-grown on mCCDA, transferred to 96 well plates containing $100 \mu \mathrm{L}$ of DNAse/RNAse free water using sterile plastic bacterial loops

239 (Sarstdat, Germany) and mixed vigorously to disrupt the bacterial cells. The cells were boiled 240 in a water bath for 10 min as described ${ }^{14}$ and centrifuged at $4000 \times \mathrm{g}$ for 10 min to pellet cell 
debris. The supernatant $(70 \mu \mathrm{L})$ was transferred to new plates with $70 \mu \mathrm{L}$ of DNAse/RNAse free water and stored at $-20^{\circ} \mathrm{C}$ until further use. DNA template made to $25 \mu \mathrm{L}$ with DNAse-RNAse free water. VS1 primer pairs for $C$. jejuni enumeration ${ }^{15}$ and cpn 60 primer sets for the identification of other strains of Campylobacter spp. ${ }^{16}$ were used. The ompA gene was targeted for the identification of Acinetobacter spp. and $A$. baumanii specific antibiotic resistance genes, bla $_{\text {oxa-51 }} b l a_{\text {oxa-23 }}$, were used as previously described ${ }^{17,18}$. Real-time PCR reactions were placed into a CFX96 thermal cycler (Bio-Rad) with an initial polymerase activation of $95^{\circ} \mathrm{C}$ for $10 \mathrm{~min}$, followed by 40 cycles of $95^{\circ} \mathrm{C}$ for $10 \mathrm{~s}, 60^{\circ} \mathrm{C}$ for $1 \mathrm{~min}$ with a final melting step of $60^{\circ} \mathrm{C}$ to $95^{\circ} \mathrm{C}$, increasing $1{ }^{\circ} \mathrm{C}$ at each cycle.

Reactions assays for unknown samples were run in duplicate.

Positive controls used for PCR screening were C. jejuni NCTC 11168 and A. baumanii ATCC 19606. Bacterial cells were harvested by centrifugation at $3000 \times \mathrm{g}$ for $10 \mathrm{~min}$, washed with 1

$\times$ PBS and DNA was extracted using the FastDNA ${ }^{\circledR}$ SPIN kit for soil (MP Biomedicals, Santa Ana, CA).

\section{Shotgun sequencing}

Thirty to $50 \mathrm{~mL}$ of wastewater collected in September 2014 was filtered onto $0.45 \mu \mathrm{m}$ sterile mixed cellulose ester membrane filters membranes and DNA extracted using the FastDNA 
bioRxiv preprint doi: https://doi.org/10.1101/367128; this version posted July 11,2018 . The copyright holder for this preprint (which was

not certified by peer review) is the author/funder. All rights reserved. No reuse allowed without permission. 


\section{Acknowledgements}

270 This study was supported by the Australian Water Recycling Centre of Excellence and the

271 Queensland Science Fund Support. The assistance of the operational staff from Queensland Urban

272 Utilities is greatly appreciated.

\section{Transparency Declarations}

274 None to declare

\section{Conflict of Interest}

276 The authors declare that there is no conflict of interest with the organization that sponsored this

277 research and publications arising from this research. 
1. Mara D. 2004. Domestic wastewater treatment in developing countries. Earthscan Publications: London, England.

2. Oragui JI, Curtis TP, Silva SA, Mara DD. 1987. The removal of excreted bacteria and viruses in deep waste stabilization ponds in Northeast Brazil. Water Sci Technolog 19(3-4): 569-573.

3. Murphy C, Carroll C, Jordan KN. 2006. Environmental survival mechanisms of the foodborne pathogen Campylobacter jejuni. J Appl Microbio 100(4): 623-632.

4. NRMMC-EPHC-AHMC. 2008. Australian guidelines for water recycling: managing health and environmental risks (Phase 2): augmentation of drinking water supplies. In Council, N. R. M. M.; Council, E. P. a. H.; Council, N. H. a. M. R., Eds. Draft for Public Comment.

5. Platts-Mills JA, Kosek M. 204. Update on the burden of Campylobacter in developing countries. Curr Opin Infect Dis 27(5): 444-450.

6. Fitzgerald C. 2015. Campylobacter. Clinics in Laboratory Medicine. 35(2): 289-298.

7. Kojima C, Kishimoto M, Ezaki T. 2015. Distribution of antimicrobial resistance in Campylobacter strains isolated from poultry at a slaughterhouse and supermarkets in Japan. Biocontrol Sci 20 (3): 179-184.

8. Teramura H, Iwasaki M, Ogihara H. 2015 Development of a novel chromogenic medium for improved Campylobacter detection from poultry samples. J Food Protect 78 (9): 1750-1755.

9. Smith S, Meade J, McGill K, Gibbons J, Bolton D, Whyte P. 2015. Restoring the selectivity of modified charcoal cefoperazone deoxycholate agar for the isolation of Campylobacter species using tazobactam, a $\beta$-lactamase inhibitor. International J Food Microbiol 210: 131-135.

10. Ugarte-Ruiz M, Florez-Cuadrado D, Wassenaar T, Porrero M, Domínguez L. 2015. Method comparison for enhanced recovery, isolation and qualitative detection of C. jejuni and C. coli from wastewater effluent samples. International J Environ Res pub health 12 (3): 2749-2764.

11. Chon JW, Hyeon JY, Yim JH, Kim JH, Song KY, Seo KH. 2012. Improvement of modified charcoal-cefoperazone-deoxycholate agar by supplementation with a high concentration of polymyxin B for detection of Campylobacter jejuni and C. coli in chicken carcass rinses. Appl Environ Microbiol 78 (5): 1624-1626.

12. Engberg J, On SLW, Harrington CS, Gerner-Smidt P. 2000. Prevalence of Campylobacter, Arcobacter, Helicobacter, and Sutterella spp. in human fecal samples as estimated by a reevaluation of isolation methods for campylobacters. J Clin Microbiol 38 (1): 286-291.

13. Eden PA, Schmidt TM, Blackmore RP, Pace NR. 1991. Phylogenetic analysis of Aquaspirillum magnetotacticum using Polymerase Chain Reaction-amplified 16S rRNA-Specific DNA. International J System Evolution Microbiol 41 (2): 324-325.

14. Denis M, Soumet C, Rivoal K, Ermel G, Blivet D, Salvat G, Colin P.1999. Development of a m-PCR assay for simultaneous identification of Campylobacter jejuni and C. coli. Lett Appl Microbiol 29 (6): 406-410.

15. Yang C, Jiang Y, Huang K, Zhu C, Yin Y. 2003. Application of real-time PCR for quantitative detection of Campylobacter jejuni in poultry, milk and environmental water. FEMS Immunol Med Microbiol 38 (3): 265-271.

16. Chaban B, Musil KM, Himsworth CG, Hill JE. 2009. Development of cpn60-based Real-Time quantitative PCR assays for the detection of 14 Campylobacter species and application to screening of canine fecal samples. Appl Environ Microbiol 75 (10): 3055-3061.

17. McConnell MJ, Pérez-Ordóñez A, Pérez-Romero P, Valencia R, Lepe JA, Vázquez-Barba I, Pachón J. 2012. Quantitative Real-Time PCR for detection of Acinetobacter baumannii colonization in the hospital environment. J Clin Microbiol 50 (4): 1412-1414.

18. Turton JF, Woodford N, Glover J, Yarde S, Kaufmann ME, Pitt TL. 2006. Identification of Acinetobacter baumannii by detection of the blaOXA-51-like carbapenemase gene intrinsic to this species. J Clin Microbiol 44 (8): 2974-2976.

19. Rosales-Reyes R, Alcántar-Curiel MD, Jarillo-Quijada MD, Gayosso-Vázquez C, Morfin-Otero M, Rodríguez-Noriega E, Santos-Preciado JI. 2015. Biofilm formation and susceptibility to polymyxin B by a highly prevalent clone of multidrug-resistant Acinetobacter baumannii from a Mexican tertiary care hospital. Chemother 61 (1), 8-14. 
20. Kaliterna V, Kaliterna M, Hrenović J, Barišić Z, Tonkić M, Goic-Barisic I. 2016. Acinetobacter baumannii in Southern Croatia: clonal lineages, biofilm formation, and resistance patterns. J Infect Dis 47 (12): 902-907.

21. Uppu DSSM, Samaddar S, Ghosh C, Paramanandham K, Shome BR, Haldar J. 2016. Amide side chain amphiphilic polymers disrupt surface established bacterial bio-films and protect mice from chronic Acinetobacter baumannii infection. Biomaterials 74: 131-143.

22. Bullman S, Corcoran D, O'Leary J, Lucey B, Byrne D, Sleator RD. 2011. Campylobacter ureolyticus: an emerging gastrointestinal pathogen? FEMS Immunol Med Microbiol 61: 228230.

23. Koziel M, Lucey B, Bullman S, Corcoran G, Sleator R. 2012. Molecular-based detection of the gastrointestinal pathogen Campylobacter ureolyticus in unpasteurized milk samples from two cattle farms in Ireland. Gut Pathogens 4 (1): 14.

24. Ferreira da Silva M, Vaz-Moreira I, Gonzalez-Pajuelo M, Nunes OC, Manaia CM. 2007. Antimicrobial resistance patterns in Enterobacteriaceae isolated from an urban wastewater treatment plant. FEMS Microbiol Ecol 60 (1): 166-176.

25. Perrilli M, Pellegrini C, Celenza G, Bellio P, Segatore B, Amicosante G. 2011. First report from Italy of blaVIM-1 and blaTEM-1 genes in Pseudomonas putida and Acinetobacter baumannii isolated from wastewater. J Chemother 23 (3): 181-182.

26. Zhang Y, Marrs CF, Simon C, Xi C. 2009. Wastewater treatment contributes to selective increase of antibiotic resistance among Acinetobacter spp. Sci Total Environ 407 (12): 37023706.

27. WHO Briefing Note - Antimicrobial Resistance: An Emerging Water, Sanitation and Hygiene Issue http://www.who.int/water sanitation health/emerging/WASH AMR/en/

28. Potron A, Poirel L, Nordmann P. 2015 Emerging broad-spectrum resistance in Pseudomonas aeruginosa and Acinetobacter baumannii: Mechanisms and epidemiology. International J Antimicrob Agents 45 (6): 568-585.

29. Anstey NM, Currie BJ, Hassell M, Palmer D, Dwyer B, Seifert H. 2002. Community-acquired bacteremic acinetobacter pneumonia in tropical Australia is caused by diverse strains of Acinetobacter baumannii, with carriage in the throat in at-risk groups. J Clin Microbiol 40 (2): 685-686.

30. Ferreira AE, Marchetti DP, De Oliveira LM, Gusatti CS, Fuentefria DB, Corção G. 2011. Presence of OXA-23-producing isolates of Acinetobacter baumannii in wastewater from hospitals in Southern Brazil. Microbial Drug Resist 17 (2): 221-227.

31. Zimmermann J, Ludwig W, Schleifer KH. 2001. DNA polynucleotide probes generated from representatives of the genus Acinetobacter and their application in fluorescence in situ hybridization of environmental samples. Sys Appl Microbiol 24 (2): 238-244.

32. Hrenovic J, Durn G, Goic-Barisic I, Kovacic A. 2014. Occurrence of an environmental Acinetobacter baumannii strain similar to a clinical isolate in paleosol from Croatia. Appl Environ Microbiol 80 (9): 2860-2866.

33. Doidge M, Allworth A, Woods M, Marshall P, Terry M, O'Brien K, Goh H, George N, Nimmo G, Schembri M, Lipman J, Paterson D. 2010. Control of an outbreak of carbapenem-resistant Acinetobacter baumannii in Australia after introduction of environmental cleaning with a commercial oxidizing disinfectant. Infect Control Hosp Epidemiol 31 (4): 418-420. 
May 2014

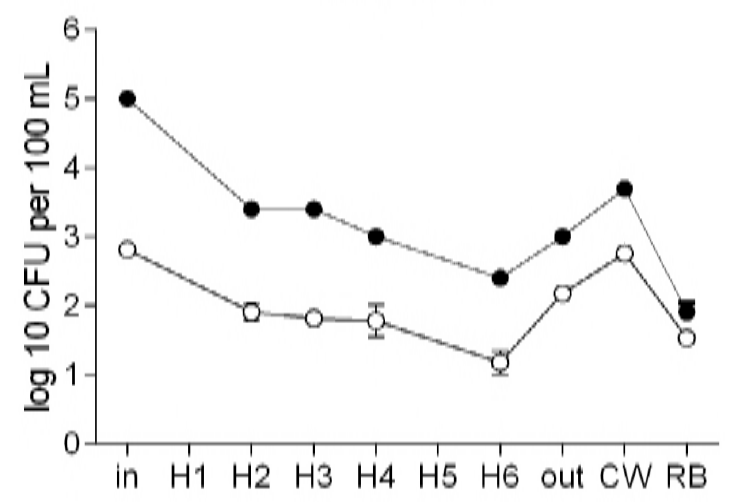

July 2014

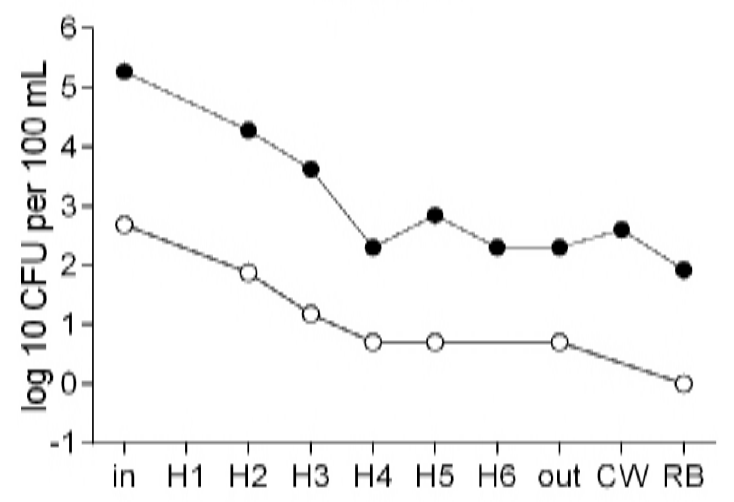

September 2014

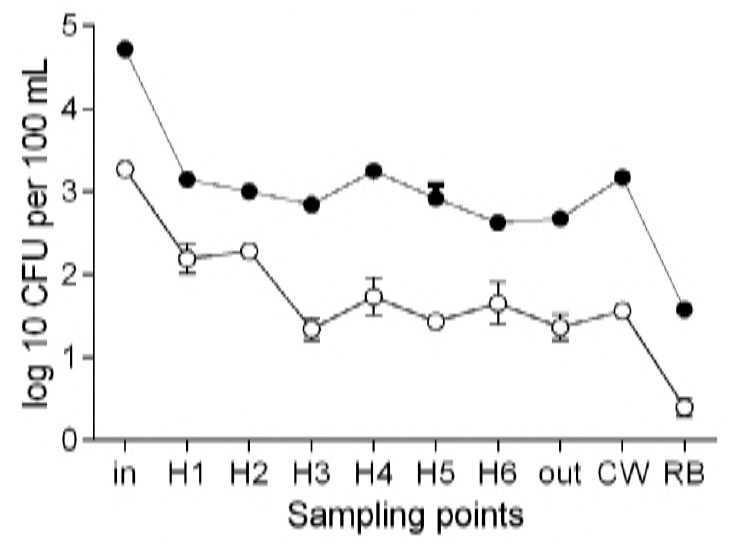

379 Figure 1. Concentrations of $A$. baumannii $(\circ)$ and E. coli $(\bullet)$ in the maturation pond at the inlet, at multiple locations (H1-H6) between baffles, at the outlet and effluent from constructed wetlands (CW) and reed beds (RB). Bars indicate standard deviation. 

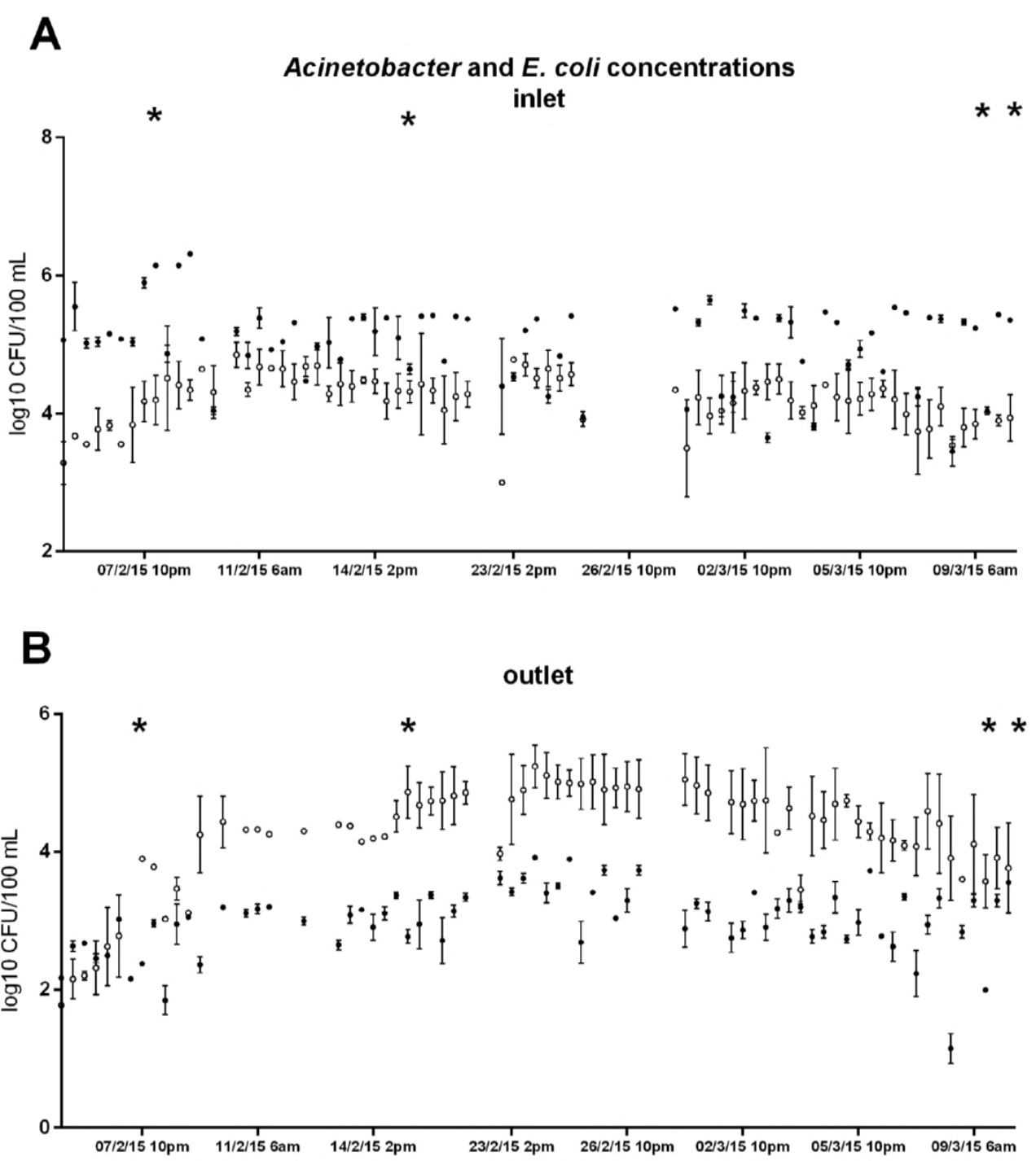

384 Figure 2. A. baumannii $(\circ)$ and E. coli $(\bullet)$ concentrations $(\log 10 \mathrm{CFU}$ per $100 \mathrm{ml})$ in the

385 inlet (A) and outlet (B). Samples were taken at 8 hourly intervals with refrigerated auto-

386 samplers, at $6 \mathrm{am}, 2 \mathrm{pm}$ and $10 \mathrm{pm}$. Bars indicate standard deviation. *Confirmatory

387 screening by real-time PCR was undertaken for colonies from these samples and results are

388 presented in Figure3. 


\section{percentage of ompA positive colonies in inlet and outlet samples}

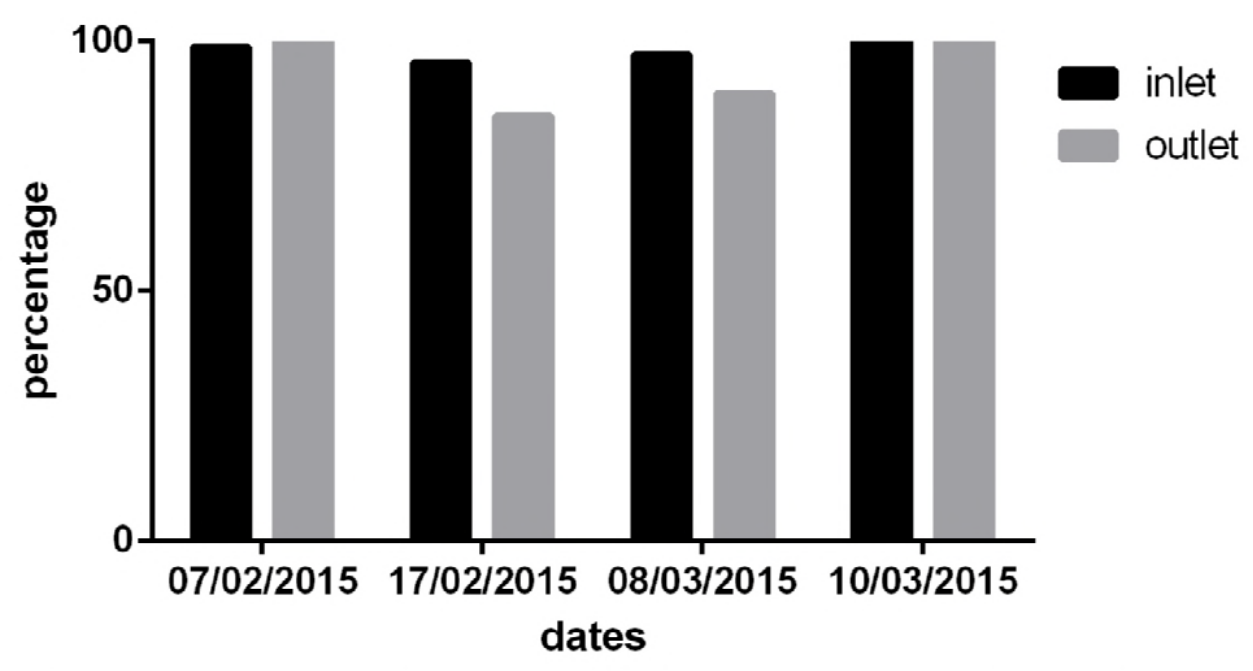

Figure 3. Percentage of ompA positive colonies out of the total number of isolates tested

392 (Table S1) on different occasions during 30 days of monitoring using auto-samplers. DNA

393 was extracted from colonies isolated on mCCDA medium originating from wastewater

394 collected at the inlet and outlet, and tested by PCR. 